\title{
Inhibitors of L-Type Calcium Channels Show Therapeutic Potential for Treating SARS-CoV-2 Infections by Preventing Virus Entry and Spread
}

Published as part of the Antiviral Therapeutics special issue.

Marco R. Straus, Miya K. Bidon, Tiffany Tang, Javier A. Jaimes, Gary R. Whittaker,* and Susan Daniel*

Cite This: https://doi.org/10.1021/acsinfecdis.1c00023

Read Online

ABSTRACT: COVID-19 is caused by a novel coronavirus, the severe acute respiratory syndrome coronavirus (CoV)-2 (SARS-CoV-2). The virus is responsible for an ongoing pandemic and concomitant public health crisis around the world. While vaccine development is proving to be highly successful, parallel drug development approaches are also critical in the response to SARS-CoV-2 and other emerging viruses. Coronaviruses require $\mathrm{Ca}^{2+}$ ions for host cell entry, and we have previously shown that $\mathrm{Ca}^{2+}$ modulates the interaction of the viral fusion peptide with host cell membranes. In an attempt to accelerate drug repurposing, we tested a panel of L-type calcium channel blocker (CCB) drugs currently developed for other conditions to determine whether they would inhibit SARSCoV-2 infection in cell culture. All the CCBs tested showed varying degrees of inhibition, with felodipine and nifedipine strongly limiting SARS-CoV-2 entry and infection in epithelial lung cells at concentrations where cell toxicity was minimal.

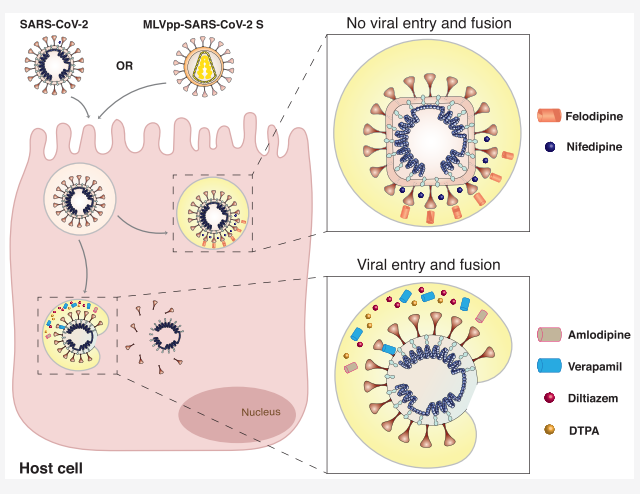
Further studies with pseudotyped particles displaying the SARS-CoV-2 spike protein suggested that inhibition occurs at the level of virus entry. Overall, our data suggest that certain CCBs have the potential to treat SARS-CoV-2 infections and are worthy of further examination for possible treatment of COVID-19.

KEYWORDS: SARS-CoV-2, viral entry, $\mathrm{Ca}^{2+}$, calcium channel blockers, viral inhibition, COVID-19 treatment

oronaviruses are major zoonotic pathogens that cause respiratory and/or enteric tract infections in a variety of species, including humans. Most of the coronaviruses that are pathogenic to humans cause only mild common cold-like disease symptoms. $^{1,2}$ However, currently a COVID-19 pandemic, caused by the severe acute respiratory syndrome (SARS)-CoV-2, poses a dramatic risk to public health worldwide. ${ }^{3}$ The virus was first identified in December 2019 in Wuhan, China and spread rapidly across the globe. ${ }^{4}$ To date, several vaccines have been approved for emergency use; ${ }^{5}$ however, the worldwide demand for these vaccines faces major difficulties due to the current limitations in vaccine production and distribution, which reiterates the need for alternative therapeutic strategies to mitigate the clinical impact of the disease. Current antiviral treatment for SARS-CoV-2 is limited to a viral polymerase inhibitor, remdesivir, used under emergency use authorization; however, this has proven to be of only limited benefit in COVID-19 patients. ${ }^{6}$ Thus, there remains an important need to identify and to provide additional drugs that can treat coronavirus infections.

The entry of the virus into the host cells is a promising target for a potential therapeutic, as it is a crucial step in the viral life cycle. ${ }^{7}$ Possible intervention steps include ACE-2 blockers, ${ }^{8}$ host cell protease inhibitors such as camostat ${ }^{9}$ and inhibitors of virus fusion, ${ }^{10,11}$ as well as monoclonal antibodies directed toward the spike. ${ }^{12}$ Previous studies have revealed that coronaviruses, such as SARS-CoV and MERS-CoV, utilize calcium ions $\left(\mathrm{Ca}^{2+}\right)$ for viral entry, via coordination of the ion by amino acid residues within the conserved fusion peptide of the viral spike $(S)$ protein. ${ }^{13,14}$ In these cases, depleting either intracellular and/or extracellular $\mathrm{Ca}^{2+}$ with chelating agents results in full or partial inhibition of viral entry and fusion. ${ }^{13,14}$ This suggests a novel way to inhibit coronavirus fusion and entry more broadly. Recently, the impact of calcium on SARSCoV-2 fusion was examined through biophysical studies, ${ }^{15,16}$ which showed broad functional similarity between SARS-CoV and SARS-CoV-2 with regard to $\mathrm{Ca}^{2+}$ interactions.

Received: January 14, 2021 


\section{Vero E6}

A
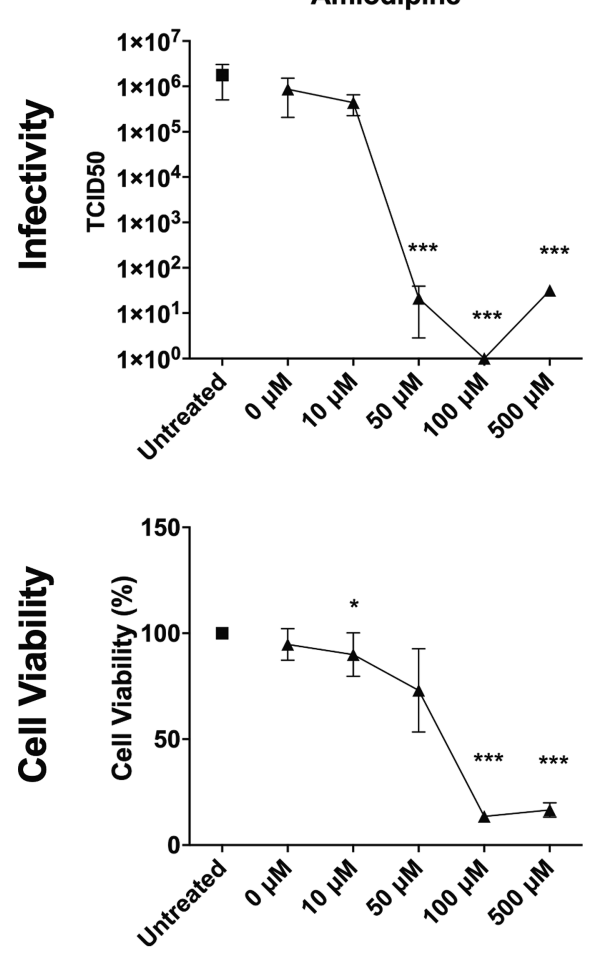

D
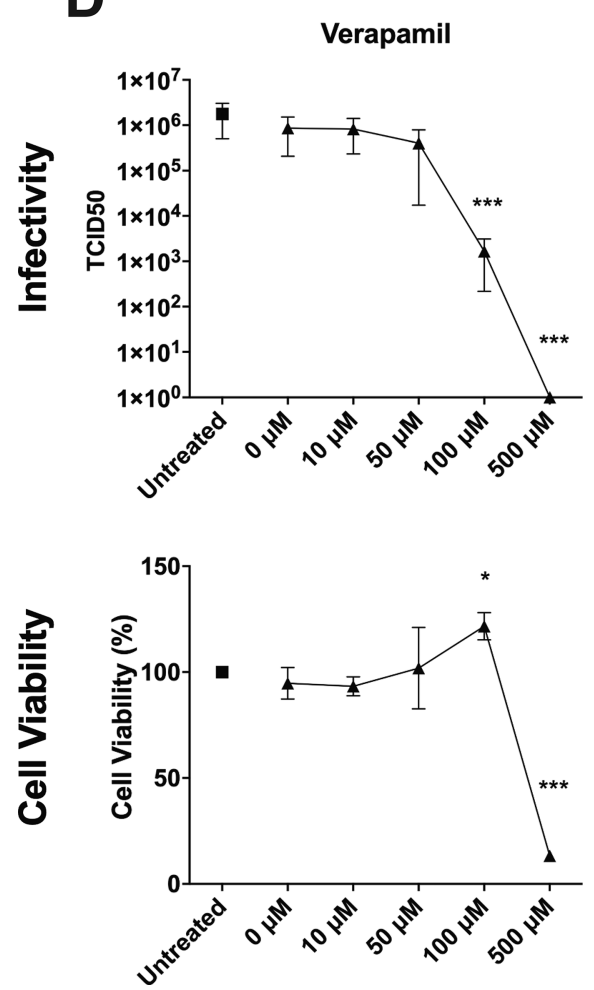

B
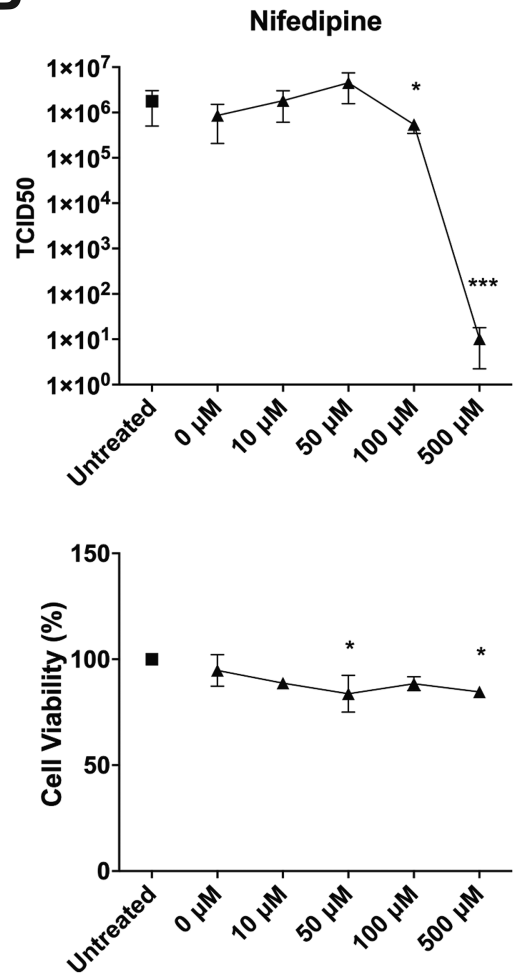

E
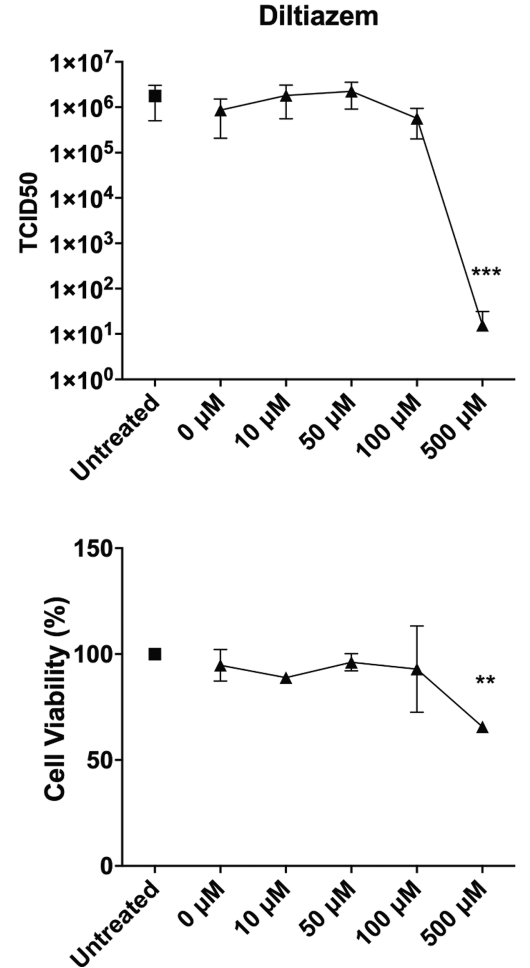

C
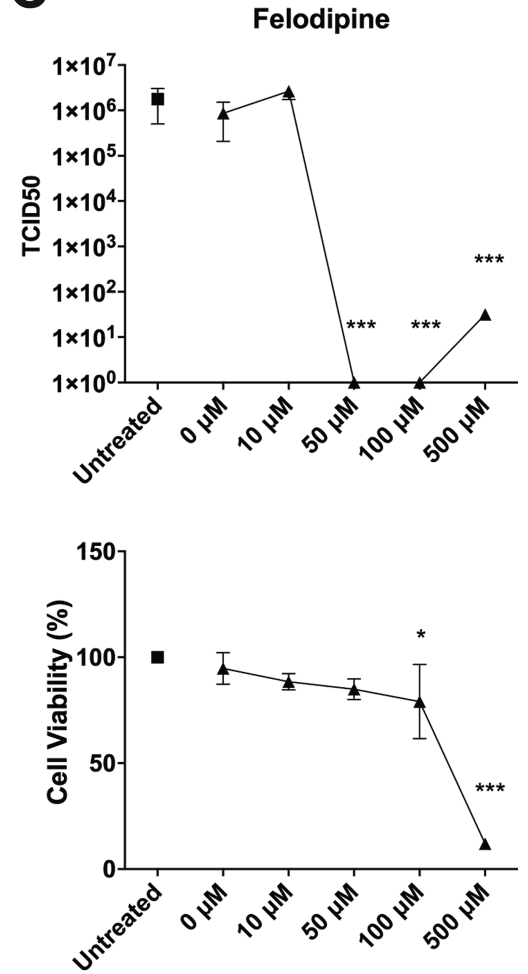

F
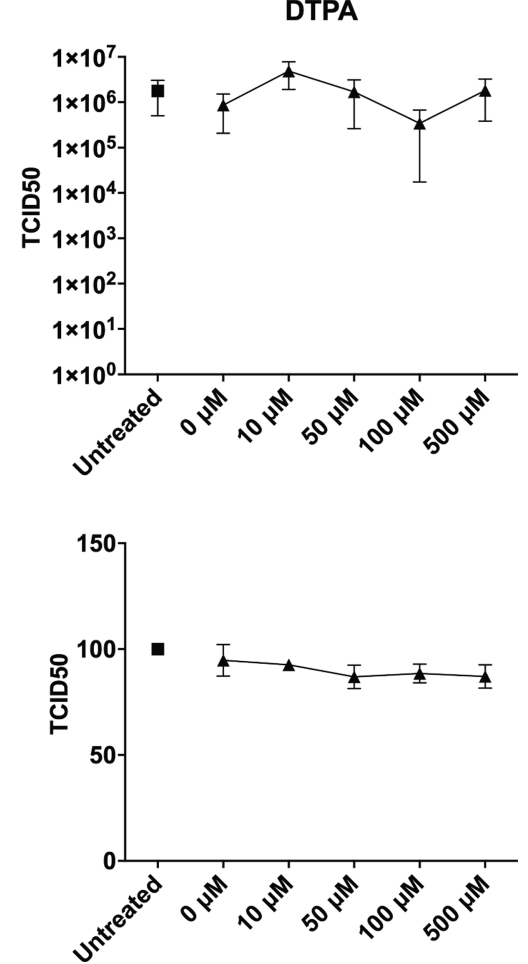

Figure 1. Inhibitory effect of five CCBs and the $\mathrm{Ca}^{2+}$ chelator DTPA on SARS-CoV-2 infection and correlation to cell viability in Vero E6 cells. Infectivity A-E: Vero E6 epithelial kidney cells were infected with SARS-CoV-2 isolate USA-WA1/2020 at a MOI of 0.1 for 24 h. The CCBs amlodipine, nifedipine, felodipine, verapamil, and diltiazem and the chelator DTPA were added to the cells at the indicated concentrations immediately after the virus. $0 \mu \mathrm{M}$ sample contained only DMSO which was used as solvent for the drugs. TCID 50 assays were performed with growth supernatants and calculated according to the Reed-Muench method. ${ }^{40}$ No bar means no virus was detected at the respective concentration. Error bars represent standard deviations $(n=3)$. Asterisks indicate statistical significance compared to the untreated control. Statistical analysis was 
Figure 1. continued

performed using an unpaired Student's $t$ test. $*=P<0.05, * *=P<0.01, * * *=P<0.001$. Cell viability A-F: Vero E6 epithelial kidney cells were treated with the indicated concentrations of amlodipine, nifedipine, felodipine, verapamil, diltiazem, and DTPA for $24 \mathrm{~h}$. After $24 \mathrm{~h}$, cell viability was measured using 3-(4,5-dimethylthiazol-2-yl)-2,5-diphenyltetrazolium bromide (MTT). Cell viability was determined by normalizing absorbance from the sample well by the average absorbance of untreated wells. As for the infections, $0 \mu \mathrm{M}$ sample contained only DMSO which was used as solvent for the drugs. Error bars represent standard deviations $(n=3)$. Asterisks indicate statistical significance compared to the untreated control. Statistical analysis was performed using an unpaired Student's $t$ test. ${ }^{*}=P<0.05, * *=P<0.01, * * *=P<0.001$.

The important role of $\mathrm{Ca}^{2+}$ in the entry of these coronaviruses prompted us to explore whether $\mathrm{Ca}^{2+}$ channel blocker (CCB) drugs inhibit SARS-CoV-2 in cell culture and have the potential to be used therapeutically. In this study, we chose five drugs from different classes that all inhibit high voltage-activated $\mathrm{Ca}^{2+}$ channels of the L-type. We selected the dihydropyridines amlodipine, nifedipine, and felodipine; the phenylalkylamine verapamil; and the benzothiazepine diltiazem. These five drugs are primarily used to treat cardiovascular diseases, including hypertension. In addition, we also tested a $\mathrm{Ca}^{2+}$ chelator drug: diethylenetriaminepentaacetic acid (DTPA), which is used to treat radioactive contamination of internal organs. We wanted to also include this $\mathrm{Ca}^{2+}$ chelator, as previous studies have shown that EGTA and BAPTA-AM (intracellular chelator) successfully inhibited entry in other coronaviruses. $^{13,14}$ Our studies reveal the potential for developing new treatment modalities for COVID-19 through the use of L-type calcium channels blockers.

While many aspects of SARS-CoV-2 entry remain unresolved, Vero E6 cells are widely used as cell line for propagation of the virus. As an initial screen of our drug panel, we infected Vero E6 cells at a relatively low MOI (0.1 infectious units per cell) in order to monitor virus propagation. We carried out a dose-response study, by adding four different concentrations of each compound $1 \mathrm{~h}$ post infection $(10 \mu \mathrm{M}$, $50 \mu \mathrm{M}, 100 \mu \mathrm{M}$, and $500 \mu \mathrm{M})$. Changes in viral propagation were then assessed after $24 \mathrm{~h}$ by $\mathrm{TCID}_{50}$ assay. We also monitored cell viability under equivalent conditions. This data is shown in Figure 1. For amlodipine, we observed a 5-log reduction of viral growth at $50 \mu \mathrm{M}$, and we were not able to detect any viral titer at a concentration of $100 \mu \mathrm{M}$ (Figure 1A). However, amlodipine also exhibited a $25 \%$ reduction of cell viability at a concentration of $50 \mu \mathrm{M}$, which increased to $90 \%$ at $100 \mu \mathrm{M}$ and $500 \mu \mathrm{M}$ (Figure $1 \mathrm{~A}$ ). In comparison, nifedipine reduced viral titers by $5 \operatorname{logs}$ at $500 \mu \mathrm{M}$ and showed about $15 \%$ cytotoxicity (Figure 1B). Felodipine completely suppressed growth of SARS-CoV-2 at a concentration of $50 \mu \mathrm{M}$ with no statistically significant cytotoxicity (Figure 1C). $100 \mu \mathrm{M}$ verapamil reduced the viral titers by $50 \%$ compared to the untreated control without a cytotoxic effect (Figure 1D). Diltiazem reduced viral growth at $500 \mu \mathrm{M}$ but also compromised cell viability at this concentration and DTPA showed no effect (Figure $1 \mathrm{E}$ and $\mathrm{F}$, respectively).

While Vero E6 cells are a good model system for SARSCoV-2 infections, this cell line is derived from epithelial kidney cells. As such, these cells may not represent the virus-drug-cell interactions in the respiratory tract and may show differences in entry pathway. Therefore, we repeated our experiments in the human lung epithelial cell line Calu-3 (Figure 2). The results for amlodipine were comparable to that found in Vero E6 cells (Figures 1A and 2A). Nifedipine and felodipine, however, significantly inhibited viral growth at lower concentrations compared to Vero E6 cells (Figure 2B and $\mathrm{C}$ ). Nifedipine reduced the viral titers by $1.5 \operatorname{logs}$ at a concentration of $100 \mu \mathrm{M}$, and no virus was detectable at 500 $\mu \mathrm{M}$, while cytotoxicity was moderate (Figure $2 \mathrm{~B}$ ). Felodipine diminished SARS-CoV-2 growth by approximately half at 10 $\mu \mathrm{M}$, and at $50 \mu \mathrm{M}$ no virus was detected with no cytotoxic effect on the cells (Figure 2C). In contrast, verapamil had a weakened inhibitory effect at $100 \mu \mathrm{M}$ compared to Vero E6 cells (Figure 2D). As in Vero E6 cells, $100 \mu \mathrm{M}$ verapamil fully suppressed viral growth but also compromised cell viability by about $90 \%$. We found very modest infection inhibition for diltiazem and DTPA at noncytotoxic concentrations of 500 $\mu \mathrm{M}$ and $100 \mu \mathrm{M}$, respectively (Figure $2 \mathrm{E}$ and $\mathrm{F}$ ).

A possible explanation for the observed difference could be found in the varying expression levels of L-type calcium channels in Vero E6 and Calu-3 cells, and we will pursue this question in our follow-up study. In this context, it is noteworthy that L-type CCBs are categorized in different chemical classes. Felodipine, nifedipine, and amlodipine belong to the class of dihydropyridines (DHPs), while diltiazem is a benzothiazepine (BZPs) and verapamil is a phenylalkamines (PAAs). All three classes bind to the $\alpha_{1}$ subunit of the L-type calcium channel, but their binding affinity is state dependent. $^{17-19}$ DHPs preferentially bind to the channel in its inactive state when there is an increased membrane potential. ${ }^{18}$ In contrast, PAAs and BZPs have a higher affinity to stimulated L-type calcium channels at a lower membrane potential. ${ }^{19}$ Hence, it is conceivable that SARS-CoV-2 infection impacts the membrane potential within cells and therefore influences the affinity of the different CCBs to the $\alpha_{1}$ subunit of L-type calcium channels. Furthermore, both diltiazem and verapamil were shown to inhibit calcium signaling from nicotinic acid adenine dinucleotide phosphate (NAADP) triggering, ${ }^{20}$ which are major activators of two pore calcium channels (TPCC). ${ }^{21}$ It was shown that using either diltiazem or verapamil to inhibit TPCC function was effective in inhibiting Ebola virus infection. $^{22}$ However, our results demonstrate modest inhibition from either diltiazem or verapamil when compared with the inhibition from felodipine, amlodipine, or nifedipine treatment. This suggests that calcium signaling resulting in proper TPCC function may not be critical for SARS-CoV-2 infection.

With amlodipine, felodipine, and nifedipine being the most promising candidates for suppression of SARS-CoV-2 growth in vivo, we determined the selectivity index (SI) (also referred to as TI, therapeutic index) of these compounds. The SI provides a measure of how safe a given drug would be for the treatment of SARS-CoV-2 infections in vivo. To calculate the SI, we determined the concentration at which they inhibit $50 \%$ of the viral growth $\left(\mathrm{EC}_{50}\right)$ and the concentration at which each drug exerts $50 \%$ cytotoxicity $\left(\mathrm{CC}_{50}\right)$. Dividing $\mathrm{CC}_{50} / \mathrm{EC}_{50}$ results in the $\mathrm{SI}$, and the higher the $\mathrm{SI}$, the more selective the drug is against the pathogen. However, it must be emphasized that while the SI determined here serves as an indicator and provides important information to consider for human application, the final therapeutic efficacy in humans 


\section{Calu-3}
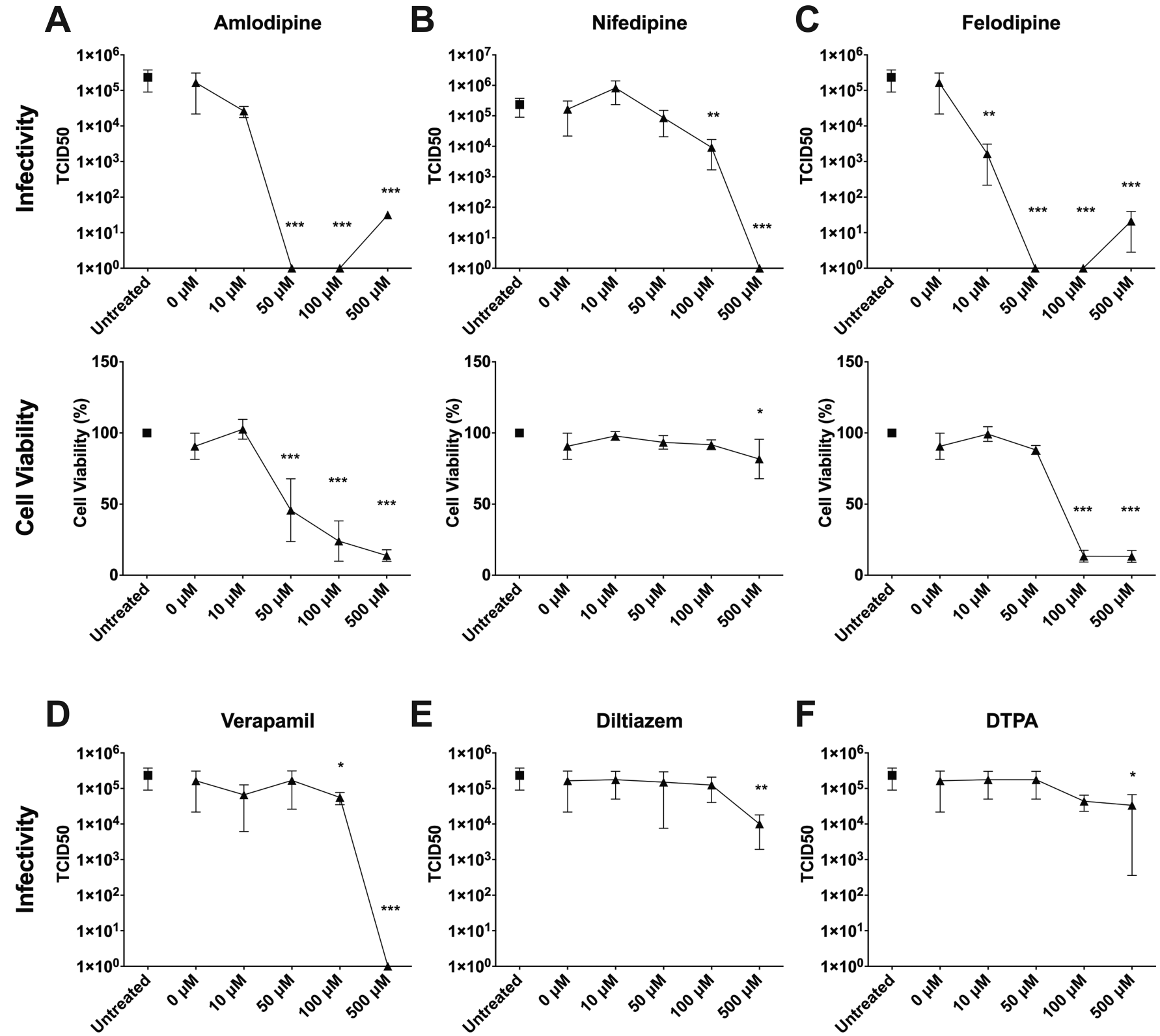

E

$\mathbf{F}$

DTPA
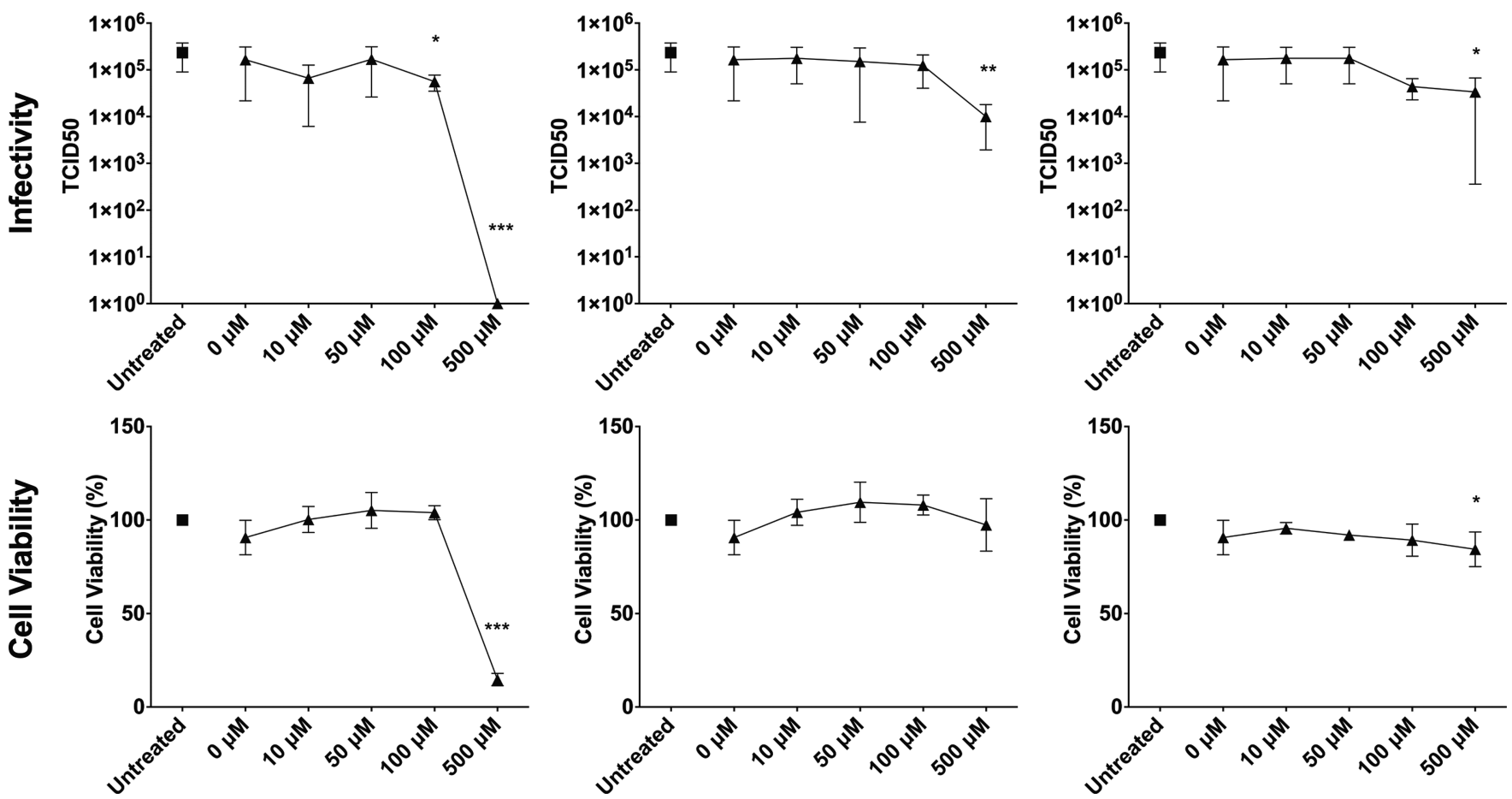

Figure 2. Inhibitory effect of five CCBs and the $\mathrm{Ca}^{2+}$ chelator DTPA on SARS-CoV-2 infection and correlation to cell viability in Calu-3 cells. Conditions for Infectivity (A-F) and Cell viability (A-F) in Calu-3 epithelial lung cells as described in the figure legend to Figure 1. Error bars represent standard deviations $(n=3)$. Asterisks indicate statistical significance compared to the untreated control. Statistical analysis was performed using an unpaired Student's $t$ test. $*=P<0.05$, ** $=P<0.01$, *** $=P<0.001$.

may differ, and potential side effects of the drugs cannot be taken into account. We used Calu-3 cells as the more relevant cell line compared to Vero cells. Cells were infected with SARS-CoV-2 and different concentrations of the respective 
drugs were applied (Figure S1). The obtained $\mathrm{EC}_{50}$ values were $10.36 \mu \mathrm{M}$ for amlodipine, $0.01255 \mu \mathrm{M}$ for felodipine, and $20.47 \mu \mathrm{M}$ for nifedipine (Figure S1A-C, Table 1). We

Table 1. $\mathrm{EC}_{50}, \mathrm{CC}_{50}$, and Selectivity Index (SI) of Amlodipine, Felodipine, and Nifedipine ${ }^{a}$

\begin{tabular}{cccc} 
& $\mathrm{EC}_{50}(\mu \mathrm{M})$ & $\mathrm{CC}_{50}(\mu \mathrm{M})$ & $\mathrm{SI}$ \\
Amlodipine & 10.36 & 27.85 & 2.688224 \\
Felodipine & 0.01255 & 122.8 & 9784.861 \\
Nifedipine & 20.47 & $>\mathrm{NNNN}$ & $>\mathrm{NNNN}$ \\
${ }^{a} \mathrm{EC}_{50}$ and $\mathrm{CC}_{50}$ were determined in Calu-3 cells. SI $=\mathrm{CC}_{50} / \mathrm{EC}_{50}$. \\
\hline
\end{tabular}

determined the $\mathrm{CC}_{50} \mathrm{~s}$ in a similar fashion using a cytotoxicity assay as described above resulting in $\mathrm{CC}_{50}$ values of $27.85 \mu \mathrm{M}$ for amlodipine and $122.8 \mu \mathrm{M}$ for felodipine (Figure S1A and B). For nifedipine, the highest tested concentration of $2 \mathrm{mM}$ did not significantly impair cell viability (Figure S1C, Table 1). The obtained SI values were 2.69 for amlodipine and 9784.86 for felodipine (Table 1). Because nifedipine did not show a significant cytotoxic effect at approximately $7 \times$ the concentration of the most efficacious antiviral concentration of 300 $\mu \mathrm{M}$, a SI value could not be reached. Hence, all three drugs seem to be highly selective against SARS-CoV-2 with felodipine and nifedipine being the most promising candidates because of their high SI score and very low cytotoxicity, respectively.

It is important to emphasize that felodipine and nifedipine work with higher efficiency in Calu-3 cells compared to Vero E6 cells (Figures 1 and 2). In this context, it is noteworthy that CCBs are believed to affect airway smooth muscle cells, which rely on L-type calcium channels for their contraction. ${ }^{23-25}$ Recently, the same CCBs tested here were shown to have a beneficial effect on the lung function of asthma patients, providing evidence that CCBs act in the lungs. ${ }^{26}$ More evidence that interference with the cellular $\mathrm{Ca}^{2+}$ balance suppresses viral growth comes from nebulizers used for asthma medications. Nebulizers are supplemented with EDTA as a preservative, which may help to deplete extracellular $\mathrm{Ca}^{2+27}$ and may provide a clue as to why asthma (despite being a respiratory illness) is not on the top ten list of chronic health problems of people who died of COVID-19.

While these results are promising, it is unclear how the efficacious doses of amlodipine, nifedipine, and felodipine found here would translate into clinical use in human patients to treat COVID-19 infections. Nevertheless, a recent report suggests that amlodipine and nifedipine reduce mortality and the risk for intubation in COVID-19 patients $^{28}$ and hence, provides an encouraging example that $\mathrm{CCBs}$ could be a viable option to fight COVID-19 infections.

The inhibition differences observed here in these two cell lines, combined with previous work from our laboratories, suggest that inhibition may occur at the level of host cell entry. To further investigate whether CCB-mediated inhibition of SARS-CoV-2 infectivity affects viral host cell entry, we utilized murine leukemia virus (MLV)-based pseudo particles (PPs) to infect both Vero E6 and Calu-3 cells. The pseudoparticles are decorated with the SARS-CoV-2 S protein ${ }^{29}$ and carry a genome encoding for luciferase, so that infected cells produce luciferase upon transduction, which is quantifiable. These virion surrogates allow for only one infection cycle without intracellular replication, and thus, inhibition of PP infection would suggest that the CCBs affect host cell entry. As a control, PPs harboring the SARS-CoV-2 S protein were shown to be several orders of magnitude more infectious than their no envelope $(\Delta$ env) counterpart (Figure S2).

To target virus entry specifically, we pretreated all cells with the drugs for $1 \mathrm{~h}$ before adding PPs carrying the SARS-CoV-2 $S$ protein (Figure 3 ). We repeated the cytotoxicity studies in which cells were incubated with the drugs for $72 \mathrm{~h}$ to match the PP experiments (Figure S3), and the trends were similar to the results in Figure 2, except that diltiazem at $500 \mu \mathrm{M}$ and DTPA after $50 \mu \mathrm{M}$ exhibited greater cytotoxicity after $72 \mathrm{~h}$ incubation in both the Vero E6 and Calu-3 cell lines. Amlodipine suppressed PP infection at $50 \mu \mathrm{M}$ in both Vero E6 and Calu-3 cells (Figure 3). Nifedipine inhibited PP infection in Vero E6 and Calu-3 cells with $500 \mu \mathrm{M}$ having the strongest effect. Felodipine inhibited PP entry in both cell lines at $50 \mu \mathrm{M}$. Consistent with what we found in the live virus infection experiments presented above, verapamil suppressed PP entry at $50 \mu \mathrm{M}$ in Calu-3 and at $100 \mu \mathrm{M}$ in Vero E6 cells. In contrast to our observations with SARS-CoV-2 live virus infections, diltiazem and DTPA also inhibited PP infections (Figures 1, 2, and 3). Diltiazem inhibited PP infection in Calu3 starting at $50 \mu \mathrm{M}$, and in Vero E6, at $500 \mu \mathrm{M}$, however, we note that diltiazem is cytotoxic to both cell lines at $500 \mu \mathrm{M}$. Although we observed that DTPA inhibits PP entry, we also noted that DTPA is cytotoxic to the cells after $72 \mathrm{~h}$ at $50 \mu \mathrm{M}$ (Vero E6) and $10 \mu \mathrm{M}$ (Calu-3), and so we believe that the inhibition could be attributed to the cytotoxicity of DTPA.

In Vero E6 cells, CoVs are believed to preferentially enter the host cells via the endocytic pathway. ${ }^{7,30}$ In contrast, in Calu-3 cells, SARS-CoV-2 spike is predominantly activated at the plasma membrane; ${ }^{7,31}$ however, specific entry pathways and fusion location remain unresolved. There is evidence from previous reports that $\mathrm{CCBs}$ inhibit other viral infections at the cell entry level, even for viruses without an apparent $\mathrm{Ca}^{2+}$ ionbinding to the fusion peptide. Influenza virus infection, for example, triggers an influx of $\mathrm{Ca}^{2+}$ that assists the endocytic uptake of the virus, with treatment by verapamil or diltiazem inhibiting viral infection. ${ }^{32-34}$ New World hemorrhagic fever arenaviruses such as Junin virus are reportedly sensitive to CCBs, and treatment with CCBs blocks the entry of the virus into the host cell. ${ }^{35} \mathrm{CCBs}$ were also shown to interfere with viral replication of several other viruses (e.g., Japanese encephalitis virus, Zika virus, and Dengue virus). ${ }^{36}$ A recently published study observed SARS-CoV-2 inhibitory activity when cells were treated with amlodipine and attributed it to the fact that amlodipine upregulates cholesterol levels which may block SARS-CoV-2 infection. ${ }^{37}$ Thus, the exact mechanism of how CCBs suppress these viruses, as well as SARSCoV-2 infection, needs to be more fully addressed. While our results point to an interference of SARS-CoV-2 at host cell entry, it is conceivable that CCB-mediated inhibition of viral spread occurs at other stages as well, including viral release. It will require further studies to determine whether CCBs interfere directly with virus-cell fusion, how these drugs may affect the different fusion pathways, and to explore whether CCBs may inhibit other cell functions that subsequently lead to inhibition of host cell entry.

Regardless of the exact mechanism, these examples demonstrate that CCBs exhibit an antiviral efficacy against a broad range of viral pathogens relevant for public health. They also show the broad requirement of $\mathrm{Ca}^{2+}$ ions for viral propagation, supported by other studies that report a $\mathrm{Ca}^{2+}$ requirement for major human pathogens like Ebola virus and 
a)
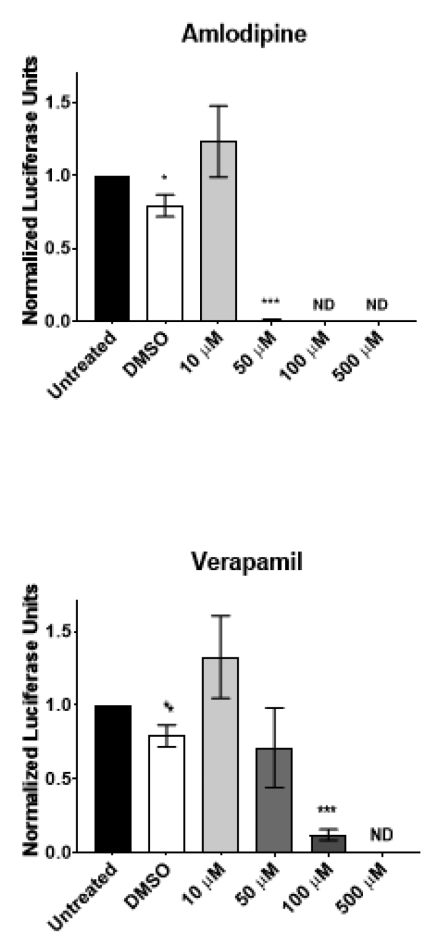

b)
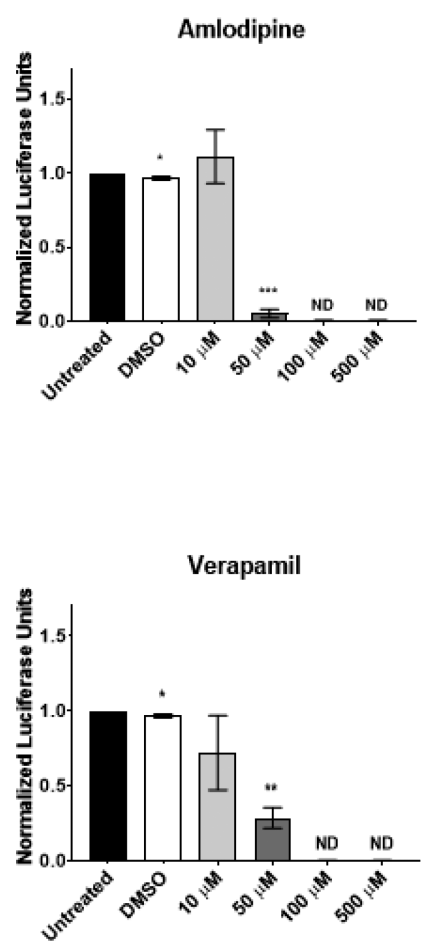

Vero E6 cells
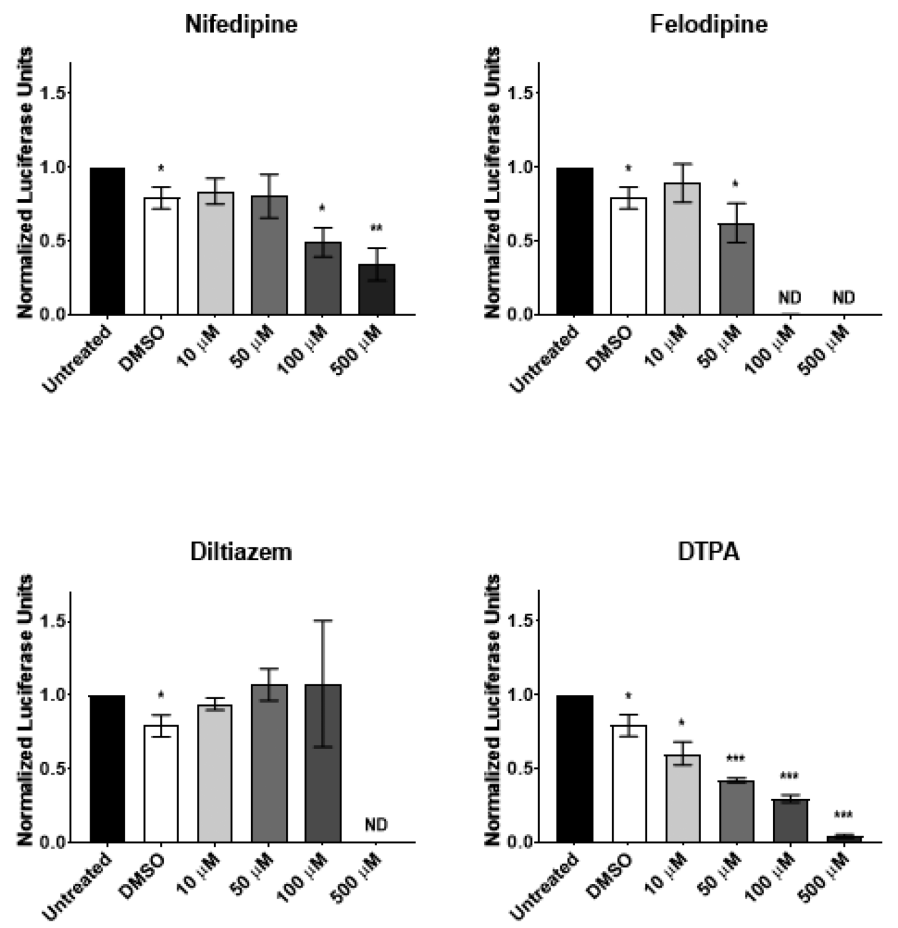

Calu-3 cells
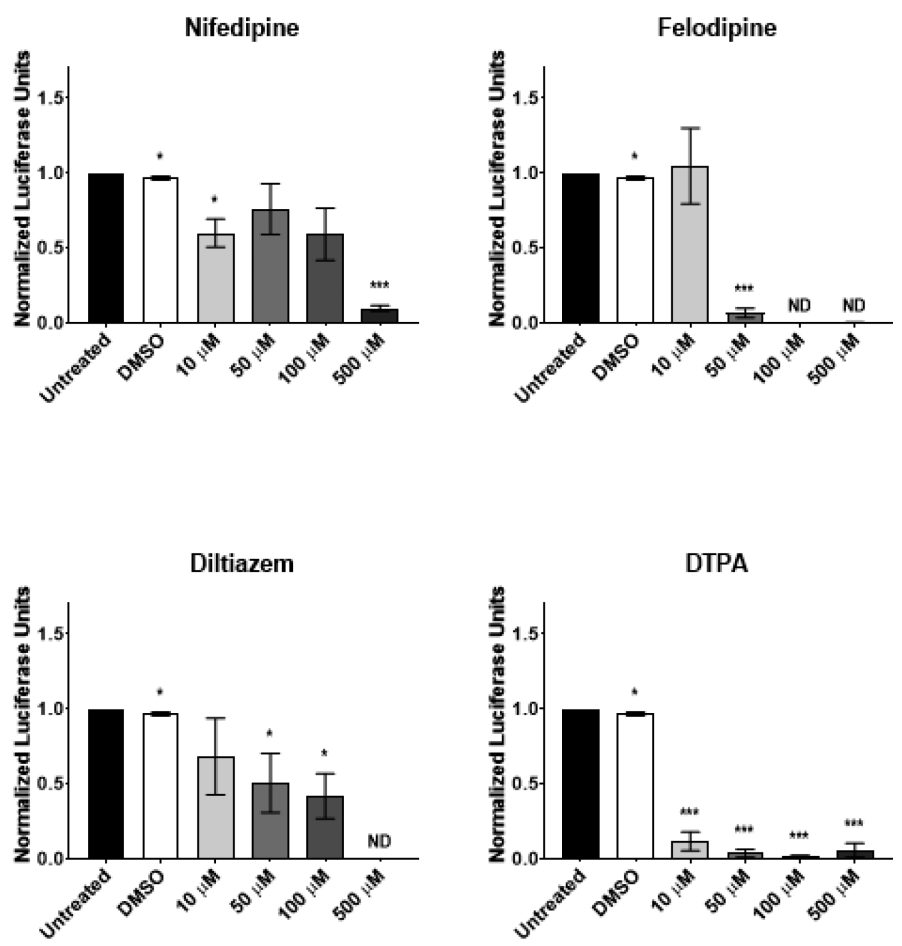

Figure 3. Pseudo particle assays of SARS-CoV-2 S in Vero E6 and Calu-3 cells. (A) Vero E6 epithelial kidney cells and (B) Calu-3 epithelial lung cells were pretreated with CCBs and DTPA for $1 \mathrm{~h}$ prior to infection with PPs carrying SARS-CoV-2 S. After $24 \mathrm{~h}$, the growth medium was changed and replenished with the drugs. $72 \mathrm{~h}$ after infection, the luciferase activity was assessed. Infectivity was normalized to the untreated sample. Error bars represent standard deviations $(n=3)$. Asterisks indicate statistical significance compared to the untreated control. Statistical analysis was performed using an unpaired Student's $t$ test. $*=P<0.05$, ** $=P<0.01$, *** $=P<0.001$.

rubella virus. ${ }^{38,39}$ Therefore, CCBs may represent a novel class of antiviral therapeutics against a broad range of major viral diseases that warrant further clinical studies, but especially to address the current crisis of COVID-19. 
In summary, the results described above are promising, and particularly felodipine and nifedipine may represent a viable treatment option against COVID-19. However, we emphasize that it is unclear how the efficacious doses found here and the SI score would translate into clinical use in human patients to treat COVID-19 infections. As a next step, a meta-analysis of patient data taking CCBs medication and the relation to the outcome and severity of COVID-19 (e.g., hospitalization, intubation, etc.) in these patients, may provide further insights about the efficacy of CCBs to inhibit SARS-CoV-2 infections in humans. This is the focus of our future studies.

\section{METHODS}

Cells and Reagents. Vero E6 and Calu-3 cells were obtained from the American Type Culture Collection (ATCC). Cells were maintained in Dulbecco's modified Eagle medium (DMEM) (Cellgro) supplemented with 25 mM HEPES (Cellgro) and 10\% HyClone FetalClone II (GE) at $37{ }^{\circ} \mathrm{C}$ and $5 \% \mathrm{CO}_{2}$. For virus infections, cells were grown in Eagle's Minimum Essential Medium (EMEM) (Cellgro) supplemented with $4 \%$ heat inactivated fetal bovine serum (FBS) (Gibco) at $37{ }^{\circ} \mathrm{C}$ and $5 \% \mathrm{CO}_{2}$.

The SARS-CoV-2 isolate USA-WA1/2020 was obtained from the Biological and Emerging Infections Resources Program (BEI Resources). Amlodipine, nifedipine, felodipine, verapamil, diltiazem, and DTPA were purchased from SigmaAldrich. 3-(4,5-Dimethylthiazol-2-yl)-2,5-diphenyltetrazolium bromide (MMT) was obtained from Thermo Fisher. Crystal violet was purchased from VWR. pCDNA3.1/SARS-CoV-2 S Wuhan $\mathrm{Hu}-1$ was generously provided by Dr. David Veesler at University of Washington.

SARS-CoV-2 Infections and TCID ${ }_{50}$ Assays. Vero E6 and Calu-3 cells were grown to confluency under biosafety level-2 (BSL-2) conditions. Cells were then transferred to the BSL-3 lab, washed with DBPS, and a volume of $200 \mu \mathrm{L}$ infection media with SARS-CoV-2 at a MOI of 0.1 was added to the cells. Cells were then incubated at $37{ }^{\circ} \mathrm{C}$ and $5 \% \mathrm{CO}_{2}$ for $1 \mathrm{~h}$ on a rocker. Cells were then supplemented with $800 \mu \mathrm{L}$ infection media (EMEM $+4 \%$ Fetal Bovine Serum), and appropriate concentrations of each drug were added. Amlodipine, nifedipine, felodipine, and verapamil were dissolved in DMSO. Therefore, DMSO was used as a control at the same volume that was applied for the highest drug concentration. After $24 \mathrm{~h}$, the supernatants were harvested and stored at $-80{ }^{\circ} \mathrm{C}$.

For the $\mathrm{TCID}_{50}$, Vero E6 cells were grown to confluency in 96 well plates and serial dilution of the supernatants were prepared. Undiluted and diluted samples were then added to the Vero E6 cells and grown for $72 \mathrm{~h}$ at $37{ }^{\circ} \mathrm{C}$ and $5 \% \mathrm{CO}_{2}$. After $72 \mathrm{~h}$, supernatants were aspirated, and cells were fixed with $4 \%$ paraformaldehyde. Cells were then stained with $0.5 \%$ crystal violet and subsequently washed with $\mathrm{dH}_{2} \mathrm{O}$. Wells were scored and analyzed for living or dead cells according to the Reed-Muench method. ${ }^{40}$

Cytotoxicity Assay. The cytotoxicity of the calcium ion blocking drugs (amlodipine, nifedipine, felodipine, diltiazem) and calcium chelator (DTPA) on Vero E6 and Calu-3 cells were determined by an 3-(4,5-dimethylthiazol-2-yl)-2,5diphenyltetrazolium bromide (MTT) assay. A total of $5 \times$ $10^{5}$ VeroE6 cells/well, and $6.7 \times 10^{5} \mathrm{Calu}-3$ cells/well were incubated in the presence of the six calcium ion blocking drugs and calcium chelator at the concentrations of $10,50,100$, and $500 \mu \mathrm{M}$ for 24 or $72 \mathrm{~h}$ at $37{ }^{\circ} \mathrm{C}$ and $5 \% \mathrm{CO}_{2}$ in a $\mathrm{CO}_{2}$ incubator. After 24 or $72 \mathrm{~h}$ incubation, cells were treated with MTT solution $(5 \mathrm{mg} / \mathrm{mL})$ and incubated for $4 \mathrm{~h}$ at $37^{\circ} \mathrm{C}$ and $5 \% \mathrm{CO}_{2}$ with rocking to allow purple formazan crystals to form. $50 \mu \mathrm{L}$ DMSO was added into each well to dissolve the crystals. The absorbance was measured at $540 \mathrm{~nm}$ in a microplate reader (Bio-Tek Instrument Co., WA, USA).

Pseudo Particle Production and Infections. Murine leukemia virus (MLV) pseudo particles production and infections were performed as previously described with minor modification. ${ }^{14}$ For PP production, HEK 293T cells were transfected with pTG-luc luciferase reporter, pCMVMLV-gagpol, and pCDNA3.1/SARS-CoV-2 S Wuhan Hu-1 to generate SARS-CoV-2 S carrying PPs. Supernatants were harvested $72 \mathrm{~h}$ post transfection and stored at $-80{ }^{\circ} \mathrm{C}$. For infections, cells were seeded in 96-well plates and DMEM containing the different CCBs and DTPA was added and incubated for $1 \mathrm{~h}$. After $1 \mathrm{~h}, 50 \mu \mathrm{L}$ PPs were added. After $24 \mathrm{~h}$, cells were replenished with DMEM containing the individual drugs at the appropriate concentration and incubated for another $48 \mathrm{~h}$ to allow expression of luciferin at sufficient levels for detection. After lysis, luciferase activity was measured using a GloMax Navigator Microplate Luminometer (Promega).

Statistical Analysis. Individual comparisons between the treatments and the control (DMSO treated) were performed for both live virus and pseudo particle assays. The results were analyzed using an unpaired Student's $t$ test using Microsoft Excel and GraphPad Prism 8 to make individual comparisons.

\section{ASSOCIATED CONTENT}

\section{SI Supporting Information}

The Supporting Information is available free of charge at https://pubs.acs.org/doi/10.1021/acsinfecdis.1c00023.

Determination of $\mathrm{EC}_{50}$ and $\mathrm{CC}_{50}$ of Amlodipine, Felodipine, and Nifedipine in Calu-3 cells (Figure S1); Characterization of the MLVpp system (Figure S2); 72 h cell viability study (Figure S3) (PDF)

\section{AUTHOR INFORMATION}

\section{Corresponding Authors}

Gary R. Whittaker - Department of Microbiology \& Immunology, College of Veterinary Medicine, Cornell University, Ithaca, New York 14853, United States; Master of Public Health Program, Cornell University, Ithaca, New York 14853, United States; Email: grw7@cornell.edu

Susan Daniel - Robert Frederick Smith School of Chemical \& Biomolecular Engineering, Cornell University, Ithaca, New York 14853, United States; 이이.org/0000-0001-77730835; Email: sd386@cornell.edu

\section{Authors}

Marco R. Straus - Department of Microbiology \& Immunology, College of Veterinary Medicine, Cornell University, Ithaca, New York 14853, United States

Miya K. Bidon - Robert Frederick Smith School of Chemical \& Biomolecular Engineering, Cornell University, Ithaca, New York 14853, United States

Tiffany Tang - Robert Frederick Smith School of Chemical \& Biomolecular Engineering, Cornell University, Ithaca, New York 14853, United States

Javier A. Jaimes - Department of Microbiology \& Immunology, College of Veterinary Medicine, Cornell 
University, Ithaca, New York 14853, United States; (1) orcid.org/0000-0001-6706-092X

Complete contact information is available at: https://pubs.acs.org/10.1021/acsinfecdis.1c00023

\section{Notes}

The authors declare no competing financial interest.

\section{ACKNOWLEDGMENTS}

This projected was funded by Fast Grant, Mercatus Center. We would like to thank Paul Jeannette for his support for all the BSL-3 work and Dr. Luis Schang, Dr. Nihal Altan-Bonnet, Dr. Fernando Martinez, Dr. Bruce Kornreich, and Dr. Hanno Andreas Ludewig for their critical input. TT is supported by the National Science Foundation Graduate Research Fellowship Program under Grant No. DGE-1650441.

\section{REFERENCES}

(1) Su, S.; Wong, G.; Shi, W.; Liu, J.; Lai, A. C. K.; Zhou, J.; Liu, W.; Bi, Y.; Gao, G. F. Epidemiology, Genetic Recombination, and Pathogenesis of Coronaviruses. Trends Microbiol. 2016, 24, 490-502.

(2) Whittaker, G. R.; Daniel, S.; Millet, J. K. Coronavirus entry: how we arrived at SARS-CoV-2. Curr. Opin. Virol. 2021, 47, 113-120.

(3) World Health Organization. Coronavirus Disease 2019 (COVID-

19) Situation Reports - 72; WHO Situation report, 2020.

(4) Wu, F.; Zhao, S.; Yu, B.; Chen, Y. M.; Wang, W.; Song, Z. G.; Hu, Y.; Tao, Z. W.; Tian, J. H.; Pei, Y. Y.; Yuan, M. L.; Zhang, Y. L.; Dai, F. H.; Liu, Y.; Wang, Q. M.; Zheng, J. J.; Xu, L.; Holmes, E. C.; Zhang, Y. Z. A new coronavirus associated with human respiratory disease in China. Nature 2020, 579, 265-269.

(5) WHO. COVID-19 vaccine tracker and landscape; Vol 3, 2020. https://www.who.int/publications/m/item/draft-landscape-of-covid19-candidate-vaccines.

(6) Grein, J.; Ohmagari, N.; Shin, D.; Diaz, G.; Asperges, E.; Castagna, A.; Feldt, T.; Green, G.; Green, M. L.; Lescure, F. X.; Nicastri, E.; Oda, R.; Yo, K.; Quiros-Roldan, E.; Studemeister, A.; Redinski, J.; Ahmed, S.; Bernett, J.; Chelliah, D.; Chen, D.; Chihara, S.; Cohen, S. H.; Cunningham, J.; Monforte, A. D.; Ismail, S.; Kato, H.; Lapadula, G.; L'Her, E.; Maeno, T.; Majumder, S.; Masssari, M.; Mora-Rillo, M.; Mutoh, Y.; Nguyen, D.; Verweij, E.; Zoufaly, A.; Osinusi, A. O.; DeZure, A.; Zhao, Y.; Zhong, L.; Chokkalingam, A.; Elboudwarej, E.; Telep, L.; Timbs, L.; Henne, I.; Sellers, S.; Cao, H.; Tan, S. K.; Winterbourne, L.; Desai, P.; Mera, R.; Gaggar, A.; Myers, R. P.; Brainard, D. M.; Childs, R.; Flanigan, T. Compassionate Use of Remdesivir for Patients with Severe Covid-19. N. Engl. J. Med. 2020, 382, 2327-2336.

(7) Tang, T.; Bidon, M.; Jaimes, J. A.; Whittaker, G. R.; Daniel, S. Coronavirus membrane fusion mechanism offers a potential target for antiviral development. Antiviral Res. 2020, 178, 104792.

(8) Yang, G.; Tan, Z.; Zhou, L.; Yang, M.; Peng, L.; Liu, J.; Cai, J.; Yang, R.; Han, J.; Huang, Y.; He, S. Effects of Angiotensin II Receptor Blockers and ACE (Angiotensin-Converting Enzyme) Inhibitors on Virus Infection, Inflammatory Status, and Clinical Outcomes in Patients with COVID-19 and Hypertension: A Single-Center Retrospective Study. Hypertension 2020, 76, 51-58.

(9) Hoffmann, M.; Kleine-Weber, H.; Schroeder, S.; Krüger, N.; Herrler, T.; Erichsen, S.; Schiergens, T. S.; Herrler, G.; Wu, N. H.; Nitsche, A.; Müller, M. A.; Drosten, C.; Pöhlmann, S. SARS-CoV-2 Cell Entry Depends on ACE2 and TMPRSS2 and Is Blocked by a Clinically Proven Protease Inhibitor. Cell 2020, 181, 271-280.e8.

(10) de Vries, R. D.; Schmitz, K. S.; Bovier, F. T.; Predella, C.; Khao, J.; Noack, D.; Haagmans, B. L.; Herfst, S.; Stearns, K. N.; Drew-Bear, J.; Biswas, S.; Rockx, B.; McGill, G.; Dorrello, N. V.; Gellman, S. H.; Alabi, C. A.; de Swart, R. L.; Moscona, A.; Porotto, M. Intranasal fusion inhibitory lipopeptide prevents direct-contact SARS-CoV-2 transmission in ferrets. Science (Washington, DC, U. S.) 2021, 371, No. 1379.
(11) Tang, T.; Jaimes, J. A.; Bidon, M. K.; Straus, M. R.; Daniel, S.; Whittaker, G. R. Proteolytic Activation of SARS-CoV-2 Spike at the S1/S2 Boundary: Potential Role of Proteases beyond Furin. ACS Infect. Dis. 2021, 7, 264.

(12) Wang, C.; Li, W.; Drabek, D.; Okba, N. M. A.; van Haperen, R.; Osterhaus, A. D. M. E.; van Kuppeveld, F. J. M.; Haagmanss, B. L.; Grosveld, F.; Bosch, B. J. A human monoclonal antibody blocking SARS-CoV-2 infection. Nat. Commun. 2020, 11, 1 DOI: 10.1038/ s41467-020-16256-y.

(13) Lai, A. L.; Millet, J. K.; Daniel, S.; Freed, J. H.; Whittaker, G. R. The SARS-CoV Fusion Peptide Forms an Extended Bipartite Fusion Platform that Perturbs Membrane Order in a Calcium-Dependent Manner. J. Mol. Biol. 2017, 429, 3875-3892.

(14) Straus, M. R.; Tang, T.; Lai, A. L.; Flegel, A.; Bidon, M. K.; Freed, J. H.; Daniel, S.; Whittaker, G. R. Ca 2+ ions promote fusion of Middle East respiratory syndrome coronavirus with host cells and increase infectivity. J. Virol. 2020, 94, 426-446.

(15) Khelashvili, G.; Plante, A.; Doktorova, M.; Weinstein, H. Ca2+dependent mechanism of membrane insertion and destabilization by the SARS-CoV-2 fusion peptide. Biophys. J. 2021, 120, 1105-1119.

(16) Lai, A. L.; Freed, J. H. SARS-CoV-2 Fusion Peptide has a Greater Membrane Perturbating Effect than SARS-CoV with Highly Specific Dependence on Ca2+. J. Mol. Biol. 2021, 433, 166946.

(17) Kurokawa, J.; Adachi-Akahane, S.; Nagao, T. 1,5-benzothiazepine binding domain is located on the extracellular side of the cardiac L-type Ca2+ channel. Mol. Pharmacol. 1997, 51, 262-268.

(18) Hockerman, G. H.; Johnson, B. D.; Scheuer, T.; Catterall, W. A. Molecular determinants of high affinity phenylalkylamine block of Ltype calcium channels. J. Biol. Chem. 1995, 270, 22119-22122.

(19) Lee, K. S.; Tsien, R. W. Mechanism of calcium channel blockade by verapamil, D600, diltiazem and nitrendipine in single dialysed heart cells. Nature 1983, 302, 790-794.

(20) Genazzani, A A; Mezna, M; Dickey, D M; Michelangeli, F; Walseth, T F; Galione, A Pharmacological properties of the Ca2+release mechanism sensitive to NAADP in the sea urchin egg. $\mathrm{Br}$. J. Pharmacol. 1997, 121, 1489-1495.

(21) Calcraft, P. J.; Ruas, M.; Pan, Z.; Cheng, X.; Arredouani, A.; Hao, X.; Tang, J.; Rietdorf, K.; Teboul, L.; Chuang, K. T.; Lin, P.; Xiao, R.; Wang, C.; Zhu, Y.; Lin, Y.; Wyatt, C. N.; Parrington, J.; Ma, J.; Evans, A. M.; Galione, A.; Zhu, M. X. NAADP mobilizes calcium from acidic organelles through two-pore channels. Nature 2009, 459, $596-600$.

(22) Sakurai, Y.; Kolokoltsov, A. A.; Chen, C. C.; Tidwell, M. W.; Bauta, W. E.; Klugbauer, N.; Grimm, C.; Wahl-Schott, C.; Biel, M.; Davey, R. A. Two-pore channels control Ebola virus host cell entry and are drug targets for disease treatment. Science (Washington, DC, $U$. S.) 2015, 347, 995-998.

(23) Löfdahl, C.-G.; Barnes, P. J. Calcium, Calcium Channel Blockade and Airways Function. Acta Pharmacol. Toxicol. 1986, 58, 91-111.

(24) Du, W.; McMahon, T. J.; Zhang, Z. S.; Stiber, J. A.; Meissner, G.; Eu, J. P. Excitation-contraction coupling in airway smooth muscle. J. Biol. Chem. 2006, 281, 30143-30151.

(25) Flores-Soto, E.; Reyes-García, J.; Sommer, B.; Montaño, L. M. Sarcoplasmic reticulum $\mathrm{Ca} 2+$ refilling is determined by L-type Ca2+ and store operated $\mathrm{Ca} 2+$ channels in guinea pig airway smooth muscle. Eur. J. Pharmacol. 2013, 721, 21-28.

(26) Chiu, K. Y.; Li, J. G.; Lin, Y. Calcium channel blockers for lung function improvement in asthma: A systematic review and metaanalysis. Ann. Allergy, Asthma, Immunol. 2017, 119, 518-523.e3.

(27) Cashman, D. P. Why the lower reported prevalence of asthma in patients diagnosed with COVID-19 validates repurposing EDTA solutions to prevent and manage treat COVID-19 disease. Med. Hypotheses 2020, 144, 110027.

(28) Solaimanzadeh, I. Nifedipine and Amlodipine Are Associated With Improved Mortality and Decreased Risk for Intubation and Mechanical Ventilation in Elderly Patients Hospitalized for COVID19. Cureus 2020, 12, e8068-e8069. 
(29) Millet, J. K.; Tang, T.; Nathan, L.; Jaimes, J. A.; Hsu, H. L.; Daniel, S.; Whittaker, G. R. Production of pseudotyped particles to study highly pathogenic coronaviruses in a biosafety level 2 setting. J. Visualized Exp. 2019, 2019, No. e59010.

(30) Matsuyama, S.; Nagata, N.; Shirato, K.; Kawase, M.; Takeda, M.; Taguchi, F. Efficient Activation of the Severe Acute Respiratory Syndrome Coronavirus Spike Protein by the Transmembrane Protease TMPRSS2. J. Virol. 2010, 84, 12658-12664.

(31) Kawase, M.; Shirato, K.; van der Hoek, L.; Taguchi, F.; Matsuyama, S. Simultaneous Treatment of Human Bronchial Epithelial Cells with Serine and Cysteine Protease Inhibitors Prevents Severe Acute Respiratory Syndrome Coronavirus Entry. J. Virol. 2012, $86,6537-6545$.

(32) Fujioka, Y.; Tsuda, M.; Nanbo, A.; Hattori, T.; Sasaki, J.; Sasaki, T.; Miyazaki, T.; Ohba, T. A Ca2+-dependent signalling circuit regulates influenza A virus internalization and infection. Nat. Commun. 2013, 4, 1-13.

(33) Nugent, K. M.; Shanley, J. D. Verapamil inhibits influenza A virus replication. Arch. Virol. 1984, 81, 163-170.

(34) Fujioka, Y.; Nishide, S.; Ose, T.; Suzuki, T.; Kato, I.; Fukuhara, H.; Fujioka, M.; Horiuchi, K.; Satoh, A. O.; Nepal, P.; Kashiwagi, S.; Wang, J.; Horiguchi, M.; Sato, Y.; Paudel, S.; Nanbo, A.; Miyazaki, T.; Hasegawa, H.; Maenaka, K.; Ohba, Y. A Sialylated Voltage-Dependent Ca 2+ Channel Binds Hemagglutinin and Mediates Influenza A Virus Entry into Mammalian Cells. Cell Host Microbe 2018, 23, 809-818.e5.

(35) Lavanya, M.; Cuevas, C. D.; Thomas, M.; Cherry, S.; Ross, S. R. siRNA screen for genes that affect Junin virus entry uncovers voltagegated calcium channels as a therapeutic target. Sci. Transl. Med. 2013, 5, 204ra130-204ra131.

(36) Wang, S.; Liu, Y.; Guo, J.; Wang, P.; Zhang, L.; Xiao, G.; Wang, W. Screening of FDA-Approved Drugs for Inhibitors of Japanese Encephalitis Virus Infection. J. Virol. 2017, 91, 1 DOI: 10.1128/ JVI.01055-17.

(37) Daniloski, Z.; Jordan, T. X.; Wessels, H. H.; Hoagland, D. A.; Kasela, S.; Legut, M.; Maniatis, S.; Mimitou, E. P.; Lu, L.; Geller, E.; Danziger, O.; Rosenberg, B. R.; Phatnani, H.; Smibert, P.; Lappalainen, T.; tenOever, B. R.; Sanjana, N. E. Identification of Required Host Factors for SARS-CoV-2 Infection in Human Cells. Cell 2021, 184, 92-105.e16.

(38) Nathan, L.; Lai, A. L.; Millet, J. K.; Straus, M. R.; Freed, J. H.; Whittaker, G. R.; Daniel, S. Calcium ions directly interact with the ebola virus fusion peptide to promote structure-function changes that enhance infection. ACS Infect. Dis. 2020, 6, 250-260.

(39) Dubé, M.; Rey, F. A.; Kielian, M. Rubella Virus: First CalciumRequiring Viral Fusion Protein. PLoS Pathog. 2014, 10, No. e1004530.

(40) Lindenbach, B. D. Measuring HCV infectivity produced in cell culture and in vivo. Methods Mol. Biol. 2009, 510, 329-336. 